\title{
Epigenetic regulation mechanism of DNA methylation and miRNAs on the expression of the $A L O X 5 A P$ gene in patients with ischemic stroke
}

\author{
XIAOSHUAI BIE $^{1 *}$, HUILING ZHAO ${ }^{2 *}$, ZHAOJING ZHANG ${ }^{1}$, XIAOOU WANG $^{1}$, YINGYING LUAN ${ }^{1}$, \\ YUANLI WANG ${ }^{1}$, SHANGDONG YANG $^{1}$, LIYAN XU ${ }^{3}$, XURAN ZHANG $^{4}$, BAIXUE ZHOU ${ }^{1}$, \\ HUI DONG ${ }^{1}$, YAN XU ${ }^{1}$, DONGZHI YANG ${ }^{5}, \mathrm{HONG} \mathrm{ZHENG}^{1}$ and $\mathrm{YING} \mathrm{HE}^{1}$
}

\begin{abstract}
${ }^{1}$ Department of Medical Genetics and Cell Biology, School of Basic Medical Sciences, Zhengzhou University, Zhengzhou, Henan 450052; ${ }^{2}$ Department of Reproductive Genetics of Anyang Maternal and Child Health Care Hospital, Anyang, Henan 455000; ${ }^{3}$ Henan Eye Institute, Henan Eye Hospital, Henan Provincial People's Hospital, Zhengzhou, Henan 450003; ${ }^{4}$ Medical Laboratory of The First Affiliated Hospital of Henan University of CM, Zhengzhou, Henan 450000; ${ }^{5}$ School of Life Sciences of Zhengzhou University, Zhengzhou, Henan 450052, P.R. China
\end{abstract}

Received May 9, 2020; Accepted October 30, 2020

DOI: $10.3892 / \mathrm{etm} .2021 .10919$

\begin{abstract}
FLAP), encoded by the arachidonate 5-lipoxygenase-activating protein (ALOX5AP) gene, can adjust the biogenesis of proinflammatory leukotrienes to increase the adhesion and permeability of the vascular internal wall. Moreover, it participates in the process of atherosclerosis and is closely associated with ischemic stroke (IS). Accumulating evidence has shown that the expression levels of the ALOX5AP gene are upregulated in patients with IS. However, the mechanism of ALOX5AP action in IS remain elusive. The present study hypothesized that epigenetic regulation, including DNA methylation and microRNA ( $\mathrm{miR} / \mathrm{miRNA}$ ) regulation, affects the expression levels of the ALOX5AP gene. Therefore, 200 patients with a first diagnosis of acute IS and 200 healthy control subjects were enrolled in the present study. Initially, the mRNA expression levels of the ALOX5AP gene were examined by reverse transcription-quantitative PCR. It was found that the mRNA levels of $A L O X 5 A P$ gene in the IS group were significantly higher compared with controls $(\mathrm{P}<0.05)$. Subsequently, the methylation status of $17 \mathrm{CpG}$ sites located in the promoter region of ALOX5AP was assessed by MethyTarget sequencing.
\end{abstract}

Correspondence to: Professor Ying He or Professor Hong Zheng, Department of Medical Genetics and Cell Biology, School of Basic Medical Sciences, Zhengzhou University, 100 Kexue Road, Zhengzhou, Henan 450052, P.R. China

E-mail: heying39@163.com

E-mail: hzheng@zzu.edu.cn

*Contributed equally

Key words: arachidonate 5-lipoxygenase-activating protein, DNA methylation, epigenetics, ischemic stroke, microRNAs
However, the levels of methylation exhibited no significant differences between IS and control groups $(\mathrm{P}>0.05)$. Moreover, the expression levels of miR-335 and miR-495 were examined as two potential miRNAs targeting the ALOX5AP gene. The expression levels of miR-335 and miR-495 in the IS group were significantly lower compared with the control group $(\mathrm{P}<0.05)$. Finally, the luciferase assay results indicated that the luciferase activity of the experimental group following co-transfection of miRNA mimic and wild-type reporter gene plasmid was significantly lower compared with the other experimental groups $(\mathrm{P}<0.05)$, suggesting that miR-335 and miR-495 could specifically bind to the 3'-untranslated region of the ALOX5AP gene, thereby downregulating its expression. The present study provided preliminary evidence demonstrating that epigenetic regulation affects the expression of the ALOX5AP gene in patients with IS.

\section{Introduction}

Ischemic stroke (IS) is a neurological disease caused by stenosis or obstruction of the cerebral artery. The main clinical manifestations of this condition are ischemia, anoxia or necrosis in the cerebral tissue of the perfused area (1). The acute phase of IS is characterized by a high degree of immune-inflammatory activation that is accompanied by increased plasma levels of cytokines, adhesion molecules and selectins (2). The immune response to acute IS is a major pathophysiological factor that is locally initiated in occluded and hypoperfused vessels and proceeds in the ischemic brain parenchyma (3). Moreover, a higher frequency of proinflammatory genes in subjects with IS may explain the immune-inflammatory activation of the acute phase of stroke (4). 5-lipoxygenase activating protein/ 5-lipoxygenase (FLAP/5-LO) is a key inflammatory mediator of the metabolic pathway, playing an important role in the biogenesis of leukotriene (LT) (5-7). FLAP, encoded by the arachidonate 5-lipoxygenase-activating protein (ALOX5AP) gene, can adjust the biogenesis of LT, activating neutrophils 
and monocytes to increase the adhesion and permeability of the internal vascular wall, contributing to atherosclerosis (8).

Ström et al (9) reported that knockout of the ALOX5AP gene in mice was associated with decreased LT production and amelioration of stroke damage. Xu et al (10) identified the correlation between ALOX5AP overexpression and the development of hypertensive stroke in rats. Domingues-Montanari et al (11) previously reported that the mRNA expression levels of $A L O X 5 A P$ in IS cases were significantly higher compared with in control subjects. However, the specific regulation that led to these higher expression levels of ALOX5AP in IS cases was not clearly detailed.

DNA methylation and microRNA (miR/miRNA) regulation are two important forms of epigenetic regulation $(12,13)$. DNA methylation mainly takes place at the cytosine base of a $\mathrm{CpG}$ dinucleotide in differentiated mammalian cells. Higher DNA methylation levels of the gene promoter region typically result in transcriptional silencing (14). In addition, miRNAs can either prevent the translation or promote the degradation of mRNA by binding to its 3'-untranslated region (3'-UTR). Accumulating evidence has revealed that miRNAs may act as essential mediators of posttranscriptional gene silencing during the development of IS (15). However, it is not clear whether some specific miRNAs affect the expression of the ALOX5AP gene in the peripheral blood of patients with IS. Consequently, miRanda (http://www.microrna.org/microrna/ home.do) was used to predict miRNAs targeting the ALOX5AP gene in the current study, and two potential miRNAs, miR-335 and mir-495 were identified, which may mediate the development of IS by the involvement of inflammatory responses in the arterial wall.

Therefore, in the present study, the effects of the epigenetic mechanisms such as DNA methylation and miRNA regulation, on the expression levels of the ALOX5AP gene in peripheral blood samples of patients with IS were investigated. Initially, higher expression levels of the ALOX5AP gene in patients with IS were identified by reverse transcription-quantitative PCR (RT-qPCR). Subsequently, the effects of DNA methylation on the expression of the ALOX5AP gene were investigated in peripheral blood samples of patients with IS. Finally, in vitro luciferase assays were performed to estimate the effects of miR-335 and miR-495 on ALOX5AP gene expression.

\section{Materials and methods}

Study populations. The study protocols were approved by the Ethics Committee on Human Research of Zhengzhou University (affiliated to both hospitals in the present study) and written informed consent was obtained from each participant. A total of 150 IS patients were recruited at the Department of Neurology in the First Affiliated Hospital of Henan University of Chinese Medicine and at the First People Hospital of Zhengzhou (Zhengzhou, China) from March 2017 to March 2018 (95 males and 55 females; mean age, $60.76 \pm 12.83$ years). These subjects were included in the initial study. A total of 50 patients with IS (30 males and 20 females; mean age, $62.42 \pm 13.04$ years) were recruited from April 2017 to July 2018 in the second cohort. IS was diagnosed by the diagnostic criteria of IS revised in the 4th session of the National Conference on Cerebrovascular Disease (16).
Brain imaging was performed by computed tomography and/ or magnetic resonance imaging. Ancillary diagnostic investigations and standardized blood tests were also performed. Patients with cerebral hemorrhage, atrial fibrillation, hyperthyroidism, cardio embolic stroke, venous thrombosis, peripheral vascular diseases, liver disorders or kidney diseases were excluded from the study. All patients were initial stroke cases. Fasting blood samples from the patients were collected within $24 \mathrm{~h}$ following stroke symptom onset.

The control groups consisted of 150 (population 1: 80 males and 70 females; mean age, $60.83 \pm 13.44$ years) and 50 (population 2: 28 males and 22 females; mean age, 58.00 \pm 13.41 years) subjects selected from the same demographic area. These subjects were well matched with the patients according to age and sex. Individuals who had cancer, cerebrovascular, cardiovascular, hepatic and renal diseases were excluded. All participants were from the Henan Han population.

Detection of ALOX5AP expression levels. Total RNA was extracted from peripheral blood using the RNA Prep Pure Blood kit (Tiangen Biotech Co., Ltd.) according to the manufacturer's recommendations and quantified using NanoDrop ${ }^{\mathrm{TM}}$ 2000 (Thermo Fisher Scientific, Inc.). Total RNA (300 ng for each participant) was reverse transcribed into cDNA using the Fast King RT kit (Tiangen Biotech Co., Ltd.) according to the manufacturer's recommendations. RT-qPCR amplification was performed with the SYBR Green PCR Master Mix kit (Takara Bio, Inc.). The following primer pairs were used for the qPCR: ALOX5AP forward, 5'-CCTGAAGCAAACATGGATCA-3', and reverse, 5'-GCTCCACTTTATGGGCAAAG-3' and $\beta$-actin forward, 5'-TGGCACCCAGCACAATGAA-3' and reverse, 5'-CTAAGTCATAGTCCGCCTAGAAGCA-3'. The reaction was performed on the 7500 Fast Real-time PCR system (Thermo Fisher Scientific, Inc.) with the following program: Initial denaturation at $95^{\circ} \mathrm{C}$ for $30 \mathrm{sec} ; 40$ cycles of $95^{\circ} \mathrm{C}$ for $3 \mathrm{sec}, 60^{\circ} \mathrm{C}$ for $30 \mathrm{sec}$ and $95^{\circ} \mathrm{C}$ for $15 \mathrm{sec}$; and dissolution curve at $60^{\circ} \mathrm{C}$ for $30 \mathrm{sec}$ and at $95^{\circ} \mathrm{C}$ for $15 \mathrm{sec} . \beta$-actin was used as the internal reference gene. Relative expression levels were calculated using the $2^{-\Delta \Delta \mathrm{Cq}}$ method (17).

Detection of miR-335 and miR-495 expression levels. miRNAs in peripheral blood plasma were extracted using the miRcute Serum/Plasma miRNA Isolation kit (Tiangen Biotech Co., Ltd.) according to the manufacturer's instructions. A total of $10 \mathrm{fmol}$ external control (Tiangen Biotech Co., Ltd.) was added into $200 \mu \mathrm{l}$ plasma prior to extraction of plasma miRNAs. Subsequently, miRNAs were reverse transcribed into cDNA using the miRcute Plus miRNA First-Strand cDNA Synthesis kit (Tiangen Biotech Co., Ltd.) according to the manufacturer's instructions. miRanda (http://www. microrna.org/microrna/home.do) was used to predict miRNAs targeting the ALOX5AP gene. The primers of the miRNAs were designed and synthesized by Tiangen Biotech Co., Ltd. And the sequences were as follows: miR-335 (Forward: 5'-ACACTCCAGCTGGGTCAAGAGCAATAACGAAA-3', Reverse: 5'-CTCAACTGGTGTCGTGGA-3'); miR-495 (Forward: 5'-GCGAAACAAACATGGTGC-3', Reverse: 5'-GCAGGGTCCGAGGTATTC-3'); the synthetic C. Elegans oligonucleotide, cel-miR-39 was used as external control (5'-UCACCGGGUGUAAAUCAGCUUG-3'). 
RT-qPCR amplification was performed using the miRcute Plus miRNA qPCR Detection kit (Tiangen Biotech Co., Ltd.). The PCR reaction was performed using the 7500 Fast Realtime PCR System (Thermo Fisher Scientific, Inc.) with the following program: Initial denaturation at $95^{\circ} \mathrm{C}$ for $15 \mathrm{~min}$, followed by five cycles of $94^{\circ} \mathrm{C}$ for $20 \mathrm{sec}, 65^{\circ} \mathrm{C}$ for $30 \mathrm{sec}$ and $72^{\circ} \mathrm{C}$ for $34 \mathrm{sec}$ without collecting fluorescent signals and 40 cycles of $94^{\circ} \mathrm{C}$ for $20 \mathrm{sec}$ and $60^{\circ} \mathrm{C}$ for $34 \mathrm{sec}$ during which fluorescent signals were collected. The dissolution curve was drawn at $60^{\circ} \mathrm{C}$ for $30 \mathrm{sec}$ and at $95^{\circ} \mathrm{C}$ for $15 \mathrm{sec}$. The relative expression levels were calculated using the $2^{-\Delta \Delta \mathrm{Cq}}$ method.

Prediction of miRNA that targets ALOX5AP. The miRanda (http://www.microrna.org/microrna/home.do) database was used to predict the miRNA that targets ALOX5AP. To evaluate binding stability and conservation, the potential miRNAs that may bind to ALOX5AP were selected based on the mirSVR and PhastCons scores assigned by the computational target prediction algorithm using MiRanda software. mirSVR represented the thermodynamic score $(\leq-0.1)$. The lower the score, the stronger the miRNA-mRNA binding stability. Phastcons represented the conservative score. The higher the score, the greater the miRNA-mRNA binding possibility. Based on these two scores, the miRNAs most likely to target ALOX5AP were selected.

DNA methylation. DNA methylation analyses were performed on $17 \mathrm{CpG}$ sites located in the promoter of the ALOX5AP gene. Genomic DNA from peripheral blood samples was extracted using the TIANamp Blood DNA kit (Tiangen Biotech Co., Ltd.) according to the manufacturer's instructions and quantified with NanoDrop 2000 (Thermo Fisher Scientific, Inc.). Bisulfite conversion of DNA was manipulated with the EZ DNA Methylation-Gold kit (Zymo Research Corp.) according to the manufacturer's recommendations. Subsequently, RT-qPCR was performed in a $20-\mu 1$ amplification reaction system including $2 \mu \mathrm{l}$ DNA sample, $1 \mathrm{X}$ reaction buffer (Takara Bio, Inc.), $2 \mathrm{mM} \mathrm{Mg}{ }^{2+}, 0.2 \mathrm{mM}$ dNTP, $0.1 \mu \mathrm{M}$ of each primer and 1 unit of HotStarTaq polymerase (Takara Bio, Inc.). The cycling program was as follows: $95^{\circ} \mathrm{C}$ for $2 \mathrm{~min}$; 11 cycles of $94^{\circ} \mathrm{C}$ for $20 \mathrm{sec}, 63-0.5^{\circ} \mathrm{C}$ per cycle for $40 \mathrm{sec}, 72^{\circ} \mathrm{C}$ for $1 \mathrm{~min}$ and 24 cycles of $94^{\circ} \mathrm{C}$ for $20 \mathrm{sec}, 65^{\circ} \mathrm{C}$ for $30 \mathrm{sec}, 72^{\circ} \mathrm{C}$ for $1 \mathrm{~min} ; 72^{\circ} \mathrm{C}$ for $2 \mathrm{~min}$. Subsequently, the samples were mixed with a specific tag sequence. A total of $20 \mu \mathrm{l}$ mixture was prepared for each reaction including $1 \mathrm{X}$ reaction buffer $(\mathrm{Q} 5$; New England BioLabs, Inc.), $0.3 \mathrm{mM}$ dNTP, $0.25 \mu \mathrm{M}$ forward primer, $0.25 \mu \mathrm{M}$ index primer, 1 unit of Q5TM DNA polymerase (New England BioLabs, Inc.) and $1 \mu 1$ diluted template. The following temperature conditions were used: $98^{\circ} \mathrm{C}$ for $30 \mathrm{sec} ; 11$ cycles of $98^{\circ} \mathrm{C}$ for $10 \mathrm{sec}, 65^{\circ} \mathrm{C}$ for $30 \mathrm{sec}, 72^{\circ} \mathrm{C}$ for $30 \mathrm{sec}$ and $72^{\circ} \mathrm{C}$ for $5 \mathrm{~min}$. Subsequently, the samples were loaded onto the Illumina NextSeq 500 (Illumina, Inc.) in order to analyze the results. Sequencing was run using the $2 \times 300 \mathrm{bp}$ paired-end mode, with an average target area sequencing depth of $>200 \mathrm{X}$ in all samples. The quality-control analysis of sequence reads was performed using FastQC software (http://www.bioinformatics.babraham.ac.uk/projects/fastqc/). Illumina sequence files were converted into FASTQ format. All reads and the reference sequences of the target region were compared by NCBI Blast (https://blast.ncbi.nlm.nih.gov/Blast. cgi). Reads that covered $90 \%$ of the target sequence or $90 \%$ bases that could completely cover the target region were classified as effective reads.

Methylation and Haplotype analysis. $\mathrm{CpG}$ islands were detected using CpGplot software (http://emboss.bioinformatics.nl/cgi-bin/emboss/cpgplot). The $\mathrm{CpG}$ island with the most $\mathrm{CpG}$ sites was selected from the $A L O X 5 A P$ gene promoter region for subsequent DNA methylation sequencing. The CpG8 site in the promoter region of the ALOX5AP gene, also known as the rs4073259 site, is considered to be a CpG-SNP. This was genotyped, and the methylation levels of individuals with different genotypes at this site were compared at different CpG sites.

Dual luciferase assay. The wild-type (WT) or mutant 3'-UTRs of ALOX5AP containing the predicted miR335-5p or miR-495-3p binding sites were synthesized and cloned into the pmirGLO vectors according to the manufacturer's instructions (Genepharm, Inc.). miR-335 mimics (5'-UCA AGAGCAAUAACGAAAA AUGUAUUUUU CGUUAUUGCUCUUGAUU-3'; $20 \mu \mathrm{M}), \quad$ miR-335 inhibitor (5'-ACAUUUUUCGUUAUUGCUCUUGA-3'; $20 \mu \mathrm{M}), \operatorname{miR}-495 \operatorname{mimics}\left(5^{\prime}\right.$-A A ACAAACAUG G U G C A C U U C U U G A A G U G C A C C A U G U U UGUUUUU-3'; $20 \mu \mathrm{M}), \quad$ miR-495 inhibitor (5 ' - A A G A A G U G C A C C A U G U U U G U U U - 3 ' ; $20 \mu \mathrm{M}$ ), negative control (NC) mimics (forward, 5'-UUCUCCGAACGUGUCACGUTT-3' and reverse, 5'-ACGUGACACGUUCGGAGAATT-3'; $20 \mu \mathrm{M}$ ) and inhibitor control (5'-CAGUACUUUUGUGUAGUACAA-3'; $20 \mu \mathrm{M}$ ) were also synthesized (Genepharm, Inc.). Luciferase reporter assays were performed using 293T cells purchased from ATCC, which were cultured in DMEM (Invitrogen; Thermo Fisher Scientific, Inc.) supplemented with 10\% FBS (Hyclone; Cytiva) at $37^{\circ} \mathrm{C}$ in a humidified incubator containing $5 \% \mathrm{CO}_{2}$. $293 \mathrm{~T}$ cells were plated at a density of $2 \times 10^{5}$ cells/well in a 24-well plate and co-transfected with plasmid $(4 \mu \mathrm{l}, 1 \mu \mathrm{g} / \mu \mathrm{l})$ and miRNA mimics ( $3 \mu 1,20 \mathrm{nM})$, mimic negative control (3 $\mu 1,20 \mathrm{nM})$, inhibitor $(3 \mu \mathrm{l}, 20 \mathrm{nM})$ and inhibitor control $(3 \mu \mathrm{l}$, $20 \mathrm{nM})$. The transfection was performed using $2 \mu \mathrm{l}$ simplefect transfection reagent (Polyplus; PolyPlus-transfection, Inc according to the manufacturer's recommendations and the cells were cultured for $48 \mathrm{~h}$. To confirm whether ALOX5AP was the direct target of miR-335 and miR-495, the 3'-UTR of $A L O X 5 A P$ was synthesized and cloned into the luciferase reporter plasmid to construct dual luciferase reporter gene plasmids including the miR-ALOX5AP 3'-UTR-wildtype and miR-ALOX5AP 3'-UTR mutant. The dual luciferase reporter gene plasmids were co-transfected into $293 \mathrm{~T}$ cells with miR-335 or miR-335 NC or miR-495 or miR-495 NC, with a blank group being transfected with the dual luciferase reporter gene plasmids alone. Luciferase activity was assayed using the Dual-Luciferase Reporter Assay system (Promega Corporation). Firefly luciferase expression levels were adjusted with reference to Renilla luciferase activity. Three independent experiments were performed for each reporter.

Cell transfection. miRNA mimics, mimic NC, inhibitor and inhibitor control were obtained from GenePharma, Inc. For 
Table I. Characteristics of two study populations.

\begin{tabular}{|c|c|c|c|c|c|c|}
\hline \multirow[b]{2}{*}{ Characteristics } & \multicolumn{3}{|c|}{ Population 1} & \multicolumn{3}{|c|}{ Population 2} \\
\hline & IS cases $(n=150)$ & Controls $(n=150)$ & P-value & IS cases $(n=50)$ & Controls $(\mathrm{n}=50)$ & P-value \\
\hline Sex (male/female) & $95 / 55$ & $80 / 70$ & 0.079 & $30 / 20$ & $28 / 22$ & 0.685 \\
\hline Age (mean $\pm \mathrm{SD}$, years $)$ & $60.76 \pm 12.83$ & $60.83 \pm 13.44$ & 0.961 & $62.42 \pm 13.04$ & $58.80 \pm 13.66$ & 0.178 \\
\hline Total cholesterol (mmol/l) & $4.81 \pm 0.78$ & $4.52 \pm 1.10$ & $0.007^{\mathrm{a}}$ & $4.78 \pm 0.84$ & $4.36 \pm 1.04$ & $0.030^{\mathrm{a}}$ \\
\hline Total triglyceride $(\mathrm{mmol} / \mathrm{l})$ & $1.66 \pm 0.77$ & $1.49 \pm 0.77$ & 0.057 & $1.60 \pm 0.83$ & $1.58 \pm 1.01$ & 0.902 \\
\hline Homocysteine $(\mu \mathrm{mol} / \mathrm{l})$ & $17.95 \pm 8.80$ & $14.71 \pm 4.02$ & $<0.001^{\mathrm{a}}$ & $19.05 \pm 7.88$ & $15.59 \pm 7.34$ & $0.025^{\mathrm{a}}$ \\
\hline Diabetes $(\mathrm{n}, \%)$ & $30(20.0 \%)$ & $13(8.6 \%)$ & $0.005^{\mathrm{a}}$ & $27(54.0 \%)$ & $11(22.0 \%)$ & $0.001^{\mathrm{a}}$ \\
\hline Hypertension $(\mathrm{n}, \%)$ & $79(52.7 \%)$ & $21(14.0 \%)$ & $<0.001^{\mathrm{a}}$ & $39(78.0 \%)$ & $26(52.0 \%)$ & $0.006^{\mathrm{a}}$ \\
\hline
\end{tabular}

${ }^{\mathrm{a}} \mathrm{P}<0.05$. IS, ischemic stroke; $\mathrm{SD}$, standard deviation.

\section{A}

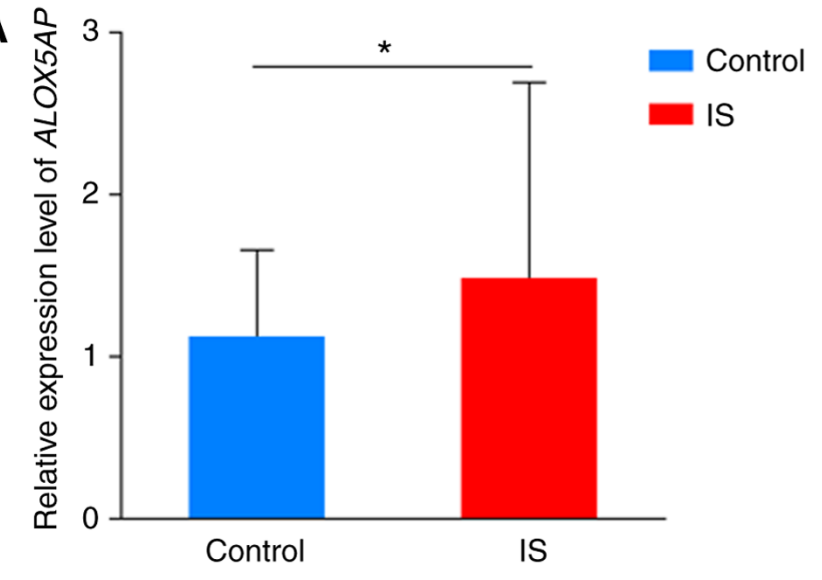

B

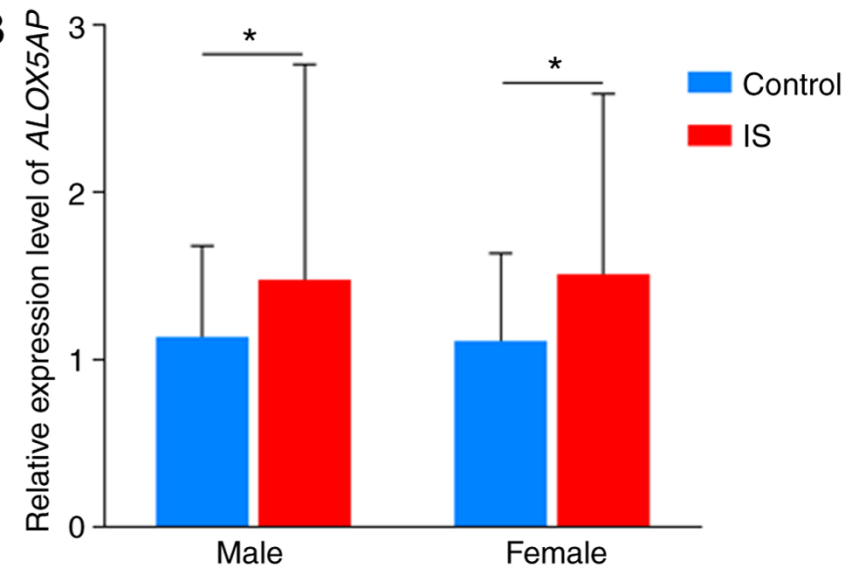

Figure 1. mRNA expression levels of the $A L O X 5 A P$ gene. (A) mRNA expression levels of the $A L O X 5 A P$ gene between the IS and control groups. (B) mRNA expression levels of the $A L O X 5 A P$ gene between the IS and control groups in different sexes. ${ }^{*} \mathrm{P}<0.05$. IS, ischemic stroke; $A L O X 5 A P$; arachidonate 5-lipoxygenase-activating protein.

the different transfection groups, 293T cells were seeded into a 6 -well plate at a density of $5 \times 10^{5}$ cells/well. After culture for $24 \mathrm{~h}$, cells were first transfected with $5 \mu \mathrm{l}$ miRNA mimics, inhibitor or corresponding mimics $\mathrm{NC}$ or inhibitor $\mathrm{NC}$ at room temperature. The transfection was performed using the RiboFECT CP transfection reagent (Guangzhou RiboBio Co., Ltd.) according to the manufacturer's protocol. At $48 \mathrm{~h}$ post-transfection, the cells were harvested for subsequent experiments. The overexpression/knockdown efficiency was determined by RT-qPCR.

Statistical analysis. All statistical analyses were performed using SPSS 21.0 (IBM Corp.). Quantitative variables were expressed as the mean \pm SD and analyzed using Student's t-test. Pearson's $\chi^{2}$ test was used to assess the differences between qualitative variables. Statistical analyses of the methylation levels and mRNA expression levels among different genotypes were performed using one-way ANOVA with Bonferroni's correction. The correlation between ALOX5AP mRNA expression level and methylation level was calculated using Pearson's correlation analysis. Unpaired Student's T-test and the Mann-Whitney U test were used for haplotype analysis of $\mathrm{CpG}$ loci of the ALOX5AP gene promoter region between ischemic stroke cases and controls. $\mathrm{P}<0.05$ was considered to indicate a statistically significant difference. Study power of sample sizes was evaluated using PASS 15.0 software (NCSS, LLC), with the results showing a power $>70 \%$.

\section{Results}

Clinical characteristics of subjects. The clinical characteristics of the study populations are shown in Table I. The levels of total cholesterol and homocysteine in IS cases were significantly higher compared with in controls $(\mathrm{P}<0.05)$. IS cases exhibited higher percentage of diabetes and hypertension in the two populations $(\mathrm{P}<0.05)$.

mRNA expression levels of ALOX5AP in IS cases and controls. The results of mRNA expression levels of $A L O X 5 A P$ are shown in Fig. 1. The mRNA expression levels of ALOX5AP in the IS cases $(1.49 \pm 1.21)$ were significantly higher compared with in controls $(1.13 \pm 0.53$; $(\mathrm{P}<0.05)$. The mRNA expression levels of IS cases (males, 1.48 \pm 1.29 ; females, $1.51 \pm 1.08$ ) were significantly higher compared with in the control subjects (males, 1.14 \pm 0.55 ; females, $1.11 \pm 0.52 ; \mathrm{P}<0.05$ ). 
A

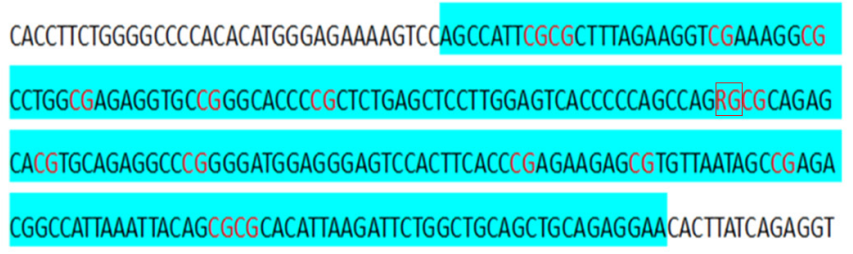

GAAGCCTTIGGAAATGCCATTCATCTTAATAGAG

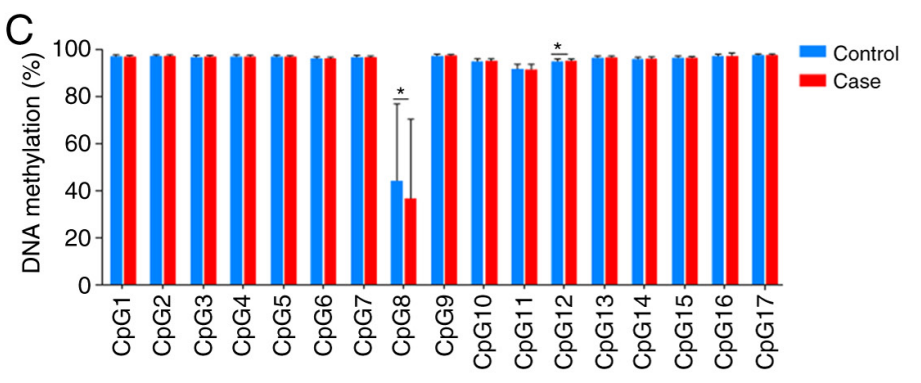

B

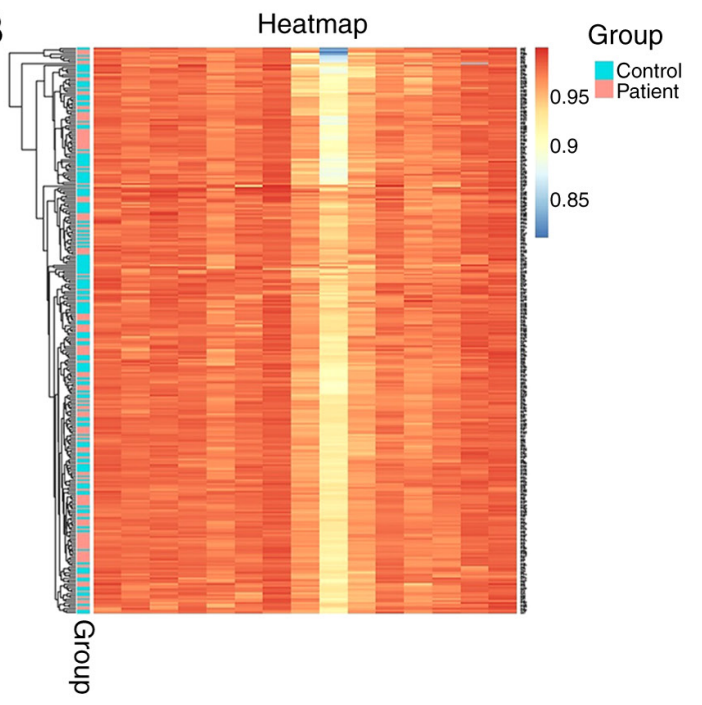

Figure 2. Epigenetic regulation of the ALOX5AP gene. (A) The base sequence of one $\mathrm{CpG}$ island of the ALOX5AP gene promoter. (B) DNA methylation cluster analysis map in the IS and control groups. (C) DNA methylation levels at $17 \mathrm{CpG}$ loci of the ALOX5AP promoter region in IS cases and controls. "P<0.05. IS, ischemic stroke; ALOX5AP; arachidonate 5-lipoxygenase-activating protein.

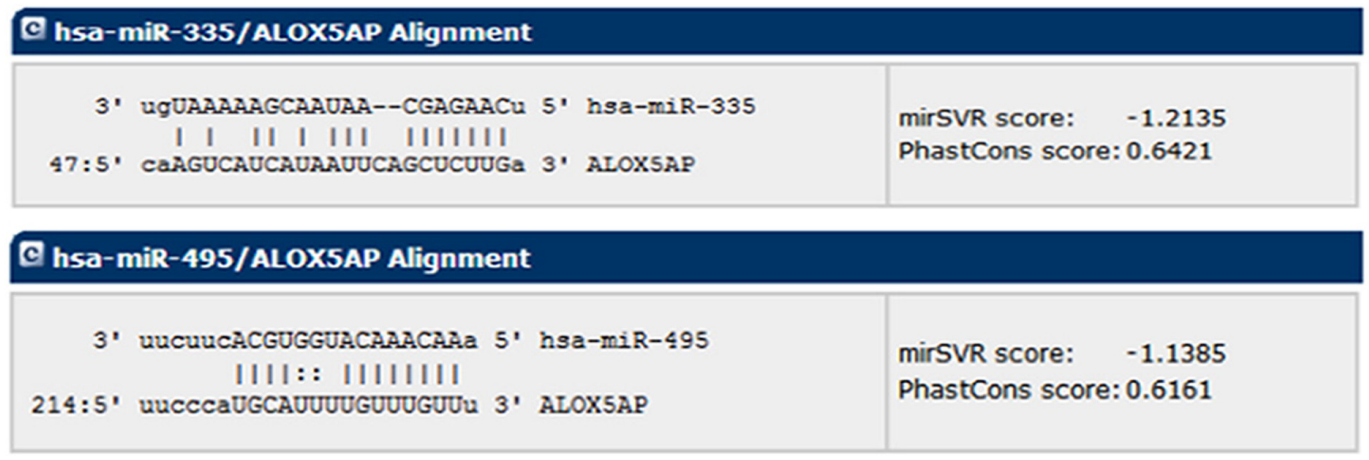

Figure 3. Prediction of miRs targeting the ALOX5AP gene. miR, microRNA; ALOX5AP; arachidonate 5-lipoxygenase-activating protein.

Bioinformatics screening of $C p G$ island region of ALOX5AP. The methylation status of the $17 \mathrm{CpG}$ sites located in the promoter region of ALOX5AP was assessed. The sequence of the $\mathrm{CpG}$ Island is shown in Fig. 2A, with the CpG8 site being a CpG-single nucleotide polymorphism (SNP) site.

Comparison of methylation levels between IS cases and control subjects. The levels of DNA methylation of the ALOX5AP gene are shown in Fig. 2B. The results indicated that hypermethylation levels were noted in both IS cases and control subjects. No significant differences were noted in IS cases and control subjects with regard to the mean DNA methylation levels in the ALOX5AP promoter region (controls, 93.62 \pm 1.94 ; IS, 93.19 \pm 1.97$)$. The mean methylation level between males and females demonstrated no significant difference (Fig. S1). A Pearson correlation analysis of the mRNA expression of ALOX5AP and the methylation level of 150 patients with IS was performed. The results revealed that the methylation levels of the ALOX5AP promoter were inversely
Table II. Haplotype analysis of CpG loci of the ALOX5AP gene promoter region between ischemic stroke cases and controls.

\begin{tabular}{|c|c|c|c|c|}
\hline No. & Target & Haplotype & $\begin{array}{c}\text { P-value } \\
\text { (t-test) }\end{array}$ & $\begin{array}{l}\text { P-value } \\
\text { (U test) }\end{array}$ \\
\hline 1 & $A L O X 5 A P$ & cecectetceccececc & $0.041458^{\mathrm{a}}$ & $0.01790895^{\mathrm{a}}$ \\
\hline 2 & $A L O X 5 A P$ & $\operatorname{ccc} c \operatorname{ccc} c \operatorname{coc} c \operatorname{ccc} c$ & 0.05102 & $0.03765977^{\mathrm{a}}$ \\
\hline 3 & $A L O X 5 A P$ & cccecectectceccec & $0.0160988^{\mathrm{a}}$ & $0.03038263^{a}$ \\
\hline 4 & $A L O X 5 A P$ & ceccecetcececetcc & 0.062201 & $0.02451332^{\mathrm{a}}$ \\
\hline 5 & $A L O X 5 A P$ & ccceccececctceccc & $0.0182789^{\mathrm{a}}$ & 0.05970357 \\
\hline 6 & $A L O X 5 A P$ & ctcecectcececcecc & $0.04632^{\mathrm{a}}$ & $0.01672627^{\mathrm{a}}$ \\
\hline 7 & ALOX5AP & tccecectcecececcc & $0.0035237^{\mathrm{a}}$ & $0.0083393^{\mathrm{a}}$ \\
\hline
\end{tabular}

${ }^{a} \mathrm{P}<0.05 . A L O X 5 A P$; arachidonate 5-lipoxygenase-activating protein.

correlated with $A L O X 5 A P$ expression in IS patients ( $\mathrm{r}=-0.175$; $\mathrm{P}=0.032$; Fig. S1). 

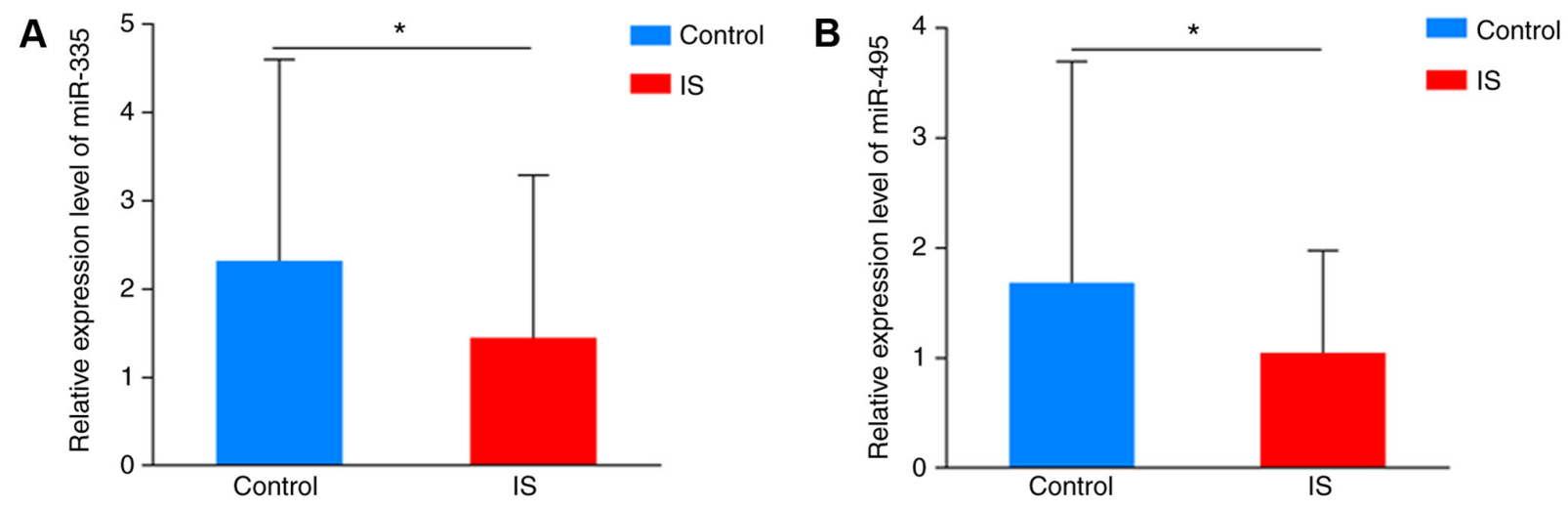

Figure 4. Expression levels of miR-335 and miR-495 in the IS and control groups. Relative expression levels of (A) miR-335 and (B) miR-495 in the IS and control groups. $\mathrm{P}<0.05$. IS, ischemic stroke; miR, microRNA
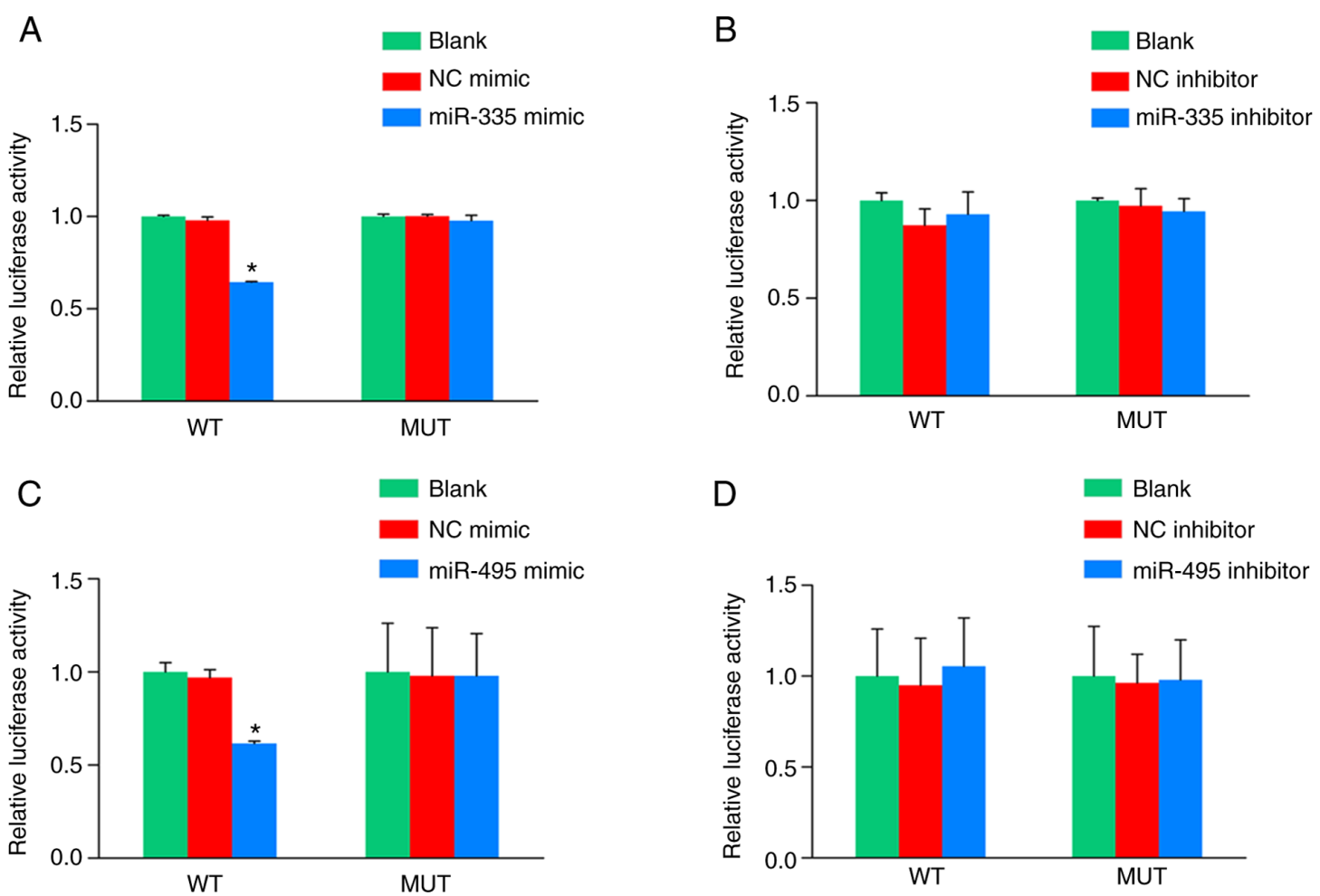

Figure 5. miR-335 and miR-495 binds to the 3'-UTR region of the ALOX5AP gene. (A and B) Relative luciferase activity of cells co-transfected with miR-335 mimic, miR-335 inhibitor and miR-335-ALOX5AP-WT-pmirGLO. (A) Relative luciferase activity in 293T co-transfected with miR-335 mimics/NC and wild-type/mutant-type ALOX5AP pmirGLO. (B) Relative luciferase activity in 293T co-transfected with miR-335 inhibitor/NC and wild-type/mutant-type ALOX5AP pmirGLO. (C) Relative luciferase activity in 293T co-transfected with miR-495 mimics/NC and wild-type/mutant-type ALOX5AP pmirGLO. (D) Results of the dual-luciferase assay in $293 \mathrm{~T}$ cells co-transfected with miR-495 inhibitor and wild-type/mutant-type ALOX5AP pmirGLO. "P<0.05. miR, microRNA; WT, wild-type; MUT, mutant; NC, negative control.

Comparison of methylation levels at $17 \mathrm{Cp}$ G loci between IS cases and control subjects. The DNA methylation levels of $17 \mathrm{CpG}$ loci of the ALOX5AP gene were measured by MethyTarget sequencing (Fig. 2C). A total of $16 \mathrm{CpG}$ loci were hypermethylated compared to those of the CpG8 site. Differential DNA methylation was noted on the CpG8 (controls, 42.70 \pm 32.56 ; IS, 37.00 \pm 33.67 ) and CpG12 (controls, 95.37 \pm 0.93 ; IS, 95.62 \pm 0.71$)$ sites between patients with IS and control subjects $(\mathrm{P}<0.05)$.

Methylation haplotype analysis of the $C p G$ island region. Haplotype analysis was applied to determine whether the haplotypes of the $\mathrm{CpG}$ island were significantly different between IS cases and control subjects. As shown in Table II, seven haplotypes were noted, which exhibited significantly higher frequency in the IS case group compared with the control subject group $(\mathrm{P}<0.05)$.

Post-transcriptional regulation of the ALOX5AP gene by miRNAs as predicted by bioinformatic analysis. miRanda (http://www.microrna.org/microrna/home.do), mirSVR scores and PhastCons scores were used to screen miR-335 and miR-495 as two miRNAs that could potentially target ALOX5AP (Fig. 3). 

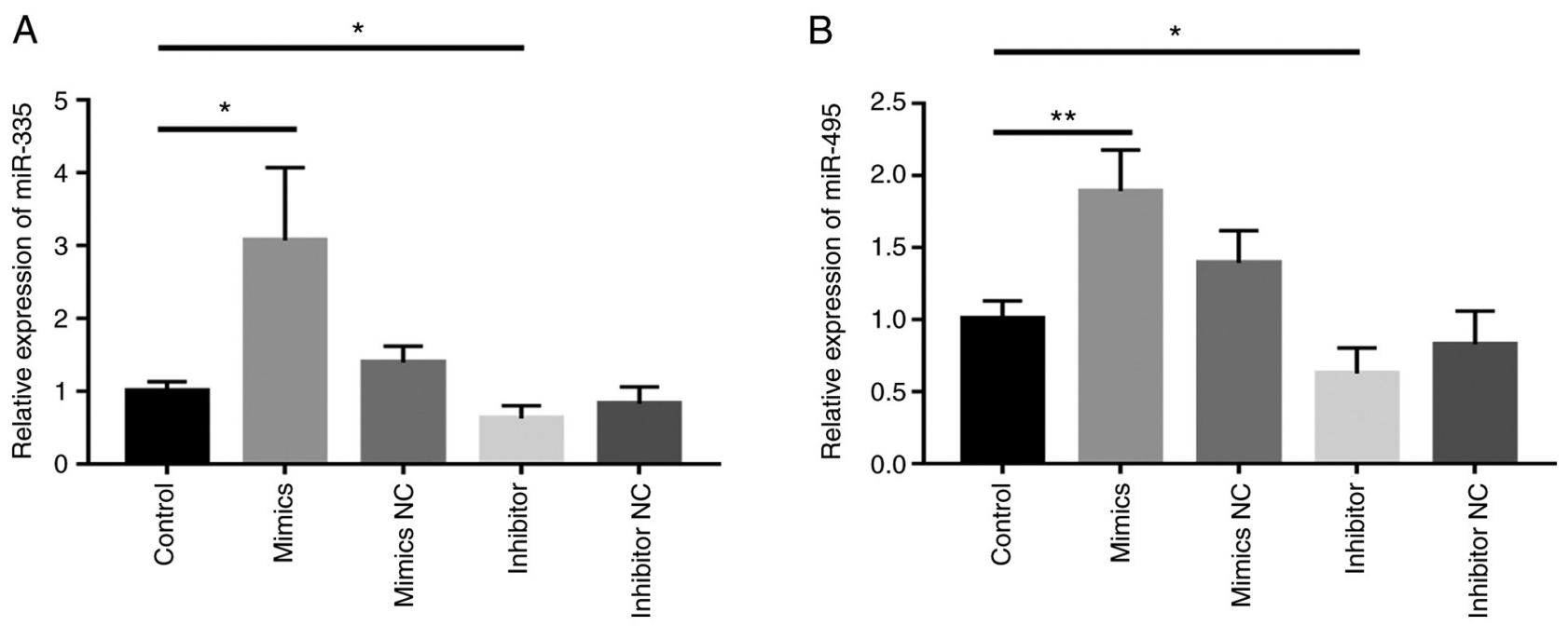

Figure 6. Effects of miR transfection on expression of miR-335 or miR-495 in $293 \mathrm{~T}$ cells. (A) In $293 \mathrm{~T}$ cells, miR-335 expression significantly increased by transfection with miR-335 mimics, but decreased by miR-335 inhibitor compared with corresponding negative controls. (B) In $293 \mathrm{~T}$ cells, miR-495 expression was significantly increased by transfection with miR-495 mimics but decreased by miR-495 inhibitor compared with corresponding negative controls. * $\mathrm{P}<0.05$ and ${ }^{* *} \mathrm{P}<0.01$. miR, microRNA; NC, negative control.

Comparison of the expression levels of miR-335 and $m i R-495$ in peripheral blood plasma. The expression levels of miR-335 and miR-495 are shown in Fig. 4. The IS cases exhibited significantly lower expression levels of miR-335 (1.49 \pm 1.84 vs. $2.32 \pm 2.28 ; \mathrm{P}=0.047)$ and $\mathrm{miR}-495(1.05 \pm 0.93$ vs. $1.69 \pm 2.01$; $\mathrm{P}=0.043)$ compared with control subjects .

miR-335 and miR-495 binds to the 3'-UTR region of the ALOX5AP gene. The results indicated that the relative luciferase activity of $293 \mathrm{~T}$ cells transfected with miR-335 mimics and miR-335-ALOX5AP-WT-pmirGLO was decreased in comparison with cells transfected with $\mathrm{NC}$ mimics and miR335-ALOX5AP-WT-pmirGLO (Fig. 5A), while there were no differences between miR-335 mimics and NC mimics transfected cells in the mutation group (Fig. 5B). Similarly, the relative luciferase activity of $293 \mathrm{~T}$ cells transfected with miR-495 mimics and miR-495-ALOX5AP-WT-pmirGLO was decreased compared with the cells transfected with NC mimics and miR-495-ALOX5AP-WT-pmirGLO (Fig. 5C), while there were no differences between miR-495 mimics and $\mathrm{NC}$ mimics transfected cells in the mutation group (Fig. 5D).

Effects of miR-335 and miR-495 on ALOX5AP expression in $293 T$ cells. 293 T cells were first transfected with miR-335 mimics, miR-495 mimics, miR-335 inhibitor, miR-495 inhibitor, corresponding mimics NC or inhibitor NC. The overexpression/knockdown efficiency was determined by RT-qPCR. The results demonstrated that transfection of miR-335 mimics or miR-495 mimics led to a significant increase in the expression levels of miR-335 $(2.423 \pm 0.466$ vs. $1.005 \pm 0.072 ; \mathrm{P}=0.039)$ or miR-495 (1.893 \pm 0.164 vs. $1.005 \pm 0.072 ; \mathrm{P}=0.005)$, respectively, compared with controls. Meanwhile, transfection of miR-335 inhibitor $(0.626 \pm 0.102$ vs. $1.005 \pm 0.072 ; \mathrm{P}=0.038)$ or $\mathrm{miR}-495$ inhibitor $(0.715 \pm 0.048$ vs. $1.006 \pm 0.080 ; \mathrm{P}=0.036$ ) resulted in a significant decrease in miR-335 or miR-495 expression, respectively, compared with corresponding negative controls (Fig. 6). Compared with the control group, ALOX5AP expression in 293T cells was

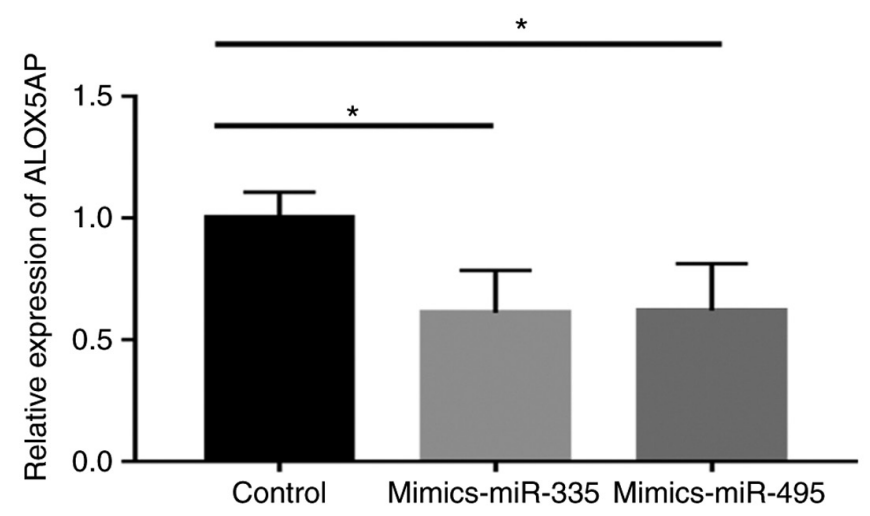

Figure 7. Relative expression of ALOX5AP in $293 \mathrm{~T}$ cells transfected with miR-335 mimics or miR-495 mimics. ${ }^{*} \mathrm{P}<0.05$. miR, microRNA; ALOX5AP; arachidonate 5-lipoxygenase-activating protein.

significantly reduced (miR-335, $0.612 \pm 0.100$ vs. $1.004 \pm 0.059$, $\mathrm{P}=0.028$; miR495, $0.6208 \pm 0.111$ vs. $1.004 \pm 0.059, \mathrm{P}=0.038$; Fig. 7).

\section{Discussion}

In the present study, a case-control study was designed to investigate the epigenetic regulation mechanisms, including DNA methylation and miRNA regulation, on the expression levels of the ALOX5AP gene in patients with IS. In 2005, Moore et al (18) detected the gene expression levels of monocytes in peripheral blood samples of 20 patients with IS and 20 control subjects using oligonucleotide microarray technologies. The results indicated significant changes in the expression levels of several genes in monocytes and the differences in gene expression levels were consistent with the central nervous system (CNS) response of IS subjects. In 2007, Sharp et al (19) confirmed that the expression levels of genes in white blood cells (WBCs) and monocytes in peripheral blood samples of patients with IS were altered. Baird (20) discovered that WBCs 
could migrate and infiltrate to the infarction and subsequently induce inflammatory response and specific changes in gene expression levels of patients with stroke. This study utilized peripheral blood samples of patients with stroke and provided information on the CNS microenvironment of the examined subjects (21). In the present study, RT-qPCR was used to detect the mRNA expression levels of the ALOX5AP gene in the peripheral blood of 150 patients with IS and 150 control subjects. The results indicated that the expression levels of the $A L O X 5 A P$ gene in the IS group were significantly higher compared with in the control subjects. The mRNA expression levels of IS cases in different sexes were higher compared with the control subjects. In 2010, Domingues-Montanari et al (11) demonstrated a difference in the expression levels of the ALOX5AP gene between IS and the control groups $(\mathrm{P}=0.003)$, which was consistent with the present findings. The ALOX5AP gene product, FLAP, has been implicated in the regulation of LTs and is recognized as an important signaling molecule in a variety of inflammatory responses. It is also implicated in the progression of atherosclerosis. Increased FLAP activity leads to the accumulation of LTs on fatty deposits of the arterial wall (22). The subsequent breakdown of these deposits by the immune system may subsequently lead to the development of atherosclerosis and may confer an increased risk of stroke. Hence, the present study inferred that the increasing expression of the ALOX5AP gene increased FLAP production in patients with IS; FLAP combined with 5-LO upregulated the biosynthesis of LT to promote the occurrence of inflammatory reactions, participate in atherosclerosis and eventually lead to IS (23). However, the specific mechanism of the regulation of the $A L O X 5 A P$ gene expression of IS patients remains unclear.

In order to investigate the differences in the expression levels of $A L O X 5 A P$ in IS, MethyTarget sequencing was used to detect the methylation levels of the promoter region of 150 patients with IS and of 150 healthy control subjects. The results indicated that the hypermethylation levels were present in both IS cases and control subjects. The overall methylation levels between the two groups did not reveal significant differences. The DNA methylation levels of $17 \mathrm{CpG}$ loci of the ALOX5AP gene were compared between the IS and the control groups and the data demonstrated that the remaining $16 \mathrm{CpG}$ loci were hypermethylated, with the exception of the CpG8 site. Differential DNA methylation was noted on the CpG8 and CpG12 sites between patients with IS and control subjects. A total of seven methylation haplotypes were noted with high frequency in the IS group. Significant differences were noted between the IS and the control groups. A Pearson correlation analysis of the mRNA expression of $A L O X 5 A P$ and methylation level of 150 patients with IS was performed. The results indicated that the methylation levels of the ALOX5AP promoter correlated inversely with $A L O X 5 A P$ expression in IS subjects ( $\mathrm{r}=-0.175, \mathrm{P}=0.032$; Fig. $\mathrm{S} 1)$. However, the hypermethylation of the promoter region of the ALOX5AP gene could not inhibit the expression levels of the gene. The introduction or removal of $\mathrm{CpG}$ dinucleotides, which are possible sites of DNA methylation, has been suggested as a potential epigenetic mechanism by which SNPs can affect gene function (24). Of note, the methylation levels of CpG8 were significantly different from other sites due to the generation of a $\mathrm{CpG}$ site. In a previous study conducted by our group, IS-associated
CpG-SNP rs4073259 correlated with differential DNA methylation, presenting the phenomenon of allele-specific methylation which may elucidate the phenotypic effects of certain genetic variants (25).

In 2013, Cao et al (26) demonstrated that the hypermethylation of the promoter region of the phospholipid-transporting ATPase ABCA1 gene was more frequent in males than in female subjects. In 2015, Lin et al (27) discovered that the methylation levels of the estrogen receptor- $\alpha$ gene were significantly lower in female patients with IS compared with control subjects, probably due to a potential protective mechanism against neurological damage in females. Therefore, the average DNA methylation levels of the ALOX5AP gene were analyzed according to sex and no significant differences were noted (Fig. S2). The results of the present study were different from those reported in the study by Lin et al (27), possibly due to population differences, phenotypic heterogeneity and a small sample size.

Bioinformatics analysis predicted that two miRNAs, miR-335 and miR-495, are most likely to target the ALOX5AP gene and downregulate its expression. Initially, the expression levels of miR-335 and miR-495 were analyzed in the plasma of 50 patients with IS and in the 50 corresponding control subjects. The results indicated that the expression levels of miR-335 and miR-495 in the IS group were significantly lower compared with the control subjects. Therefore, it was hypothesized that binding of miR-335 and miR-495 to the 3'-UTR region of the ALOX5AP gene may inhibit the expression levels of this gene. To confirm this hypothesis, a WT and mutant reporter gene plasmid was constructed containing miR-335 and miR-495 seed regions. The luciferase activity of the different groups was assessed and the potential of miR-335 and miR-495 to target the ALOX5AP gene was examined by co-transfection of miRNA mimics, mimic negative control, inhibitor, inhibitor negative control and recombinant plasmids. The results indicated that the luciferase activity of the experimental group with co-transfected miRNA mimic and WT reporter gene plasmid was significantly lower compared with the other experimental groups, suggesting that miR-335 and miR-495 could specifically bind to the 3'-UTR of the ALOX5AP gene, thereby downregulating its expression.

In summary, the present study demonstrated that the mRNA expression levels of $A L O X 5 A P$ were significantly higher in the IS cases compared with in control subjects. However, the methylation levels of the $A L O X 5 A P$ promoter correlated inversely with ALOX 5AP expression in IS cases. miR-335 and miR-495 are lowly expressed in the peripheral blood plasma of IS patients, act on the 3'-UTR region of ALOX5AP gene by negatively regulating its post-transcriptional expression, leading to the increased expression of ALOX5AP gene in the IS group. The differential regulation mechanism of the gene expression is an extremely complex process involving various factors. The specific differentiation mechanism of the ALOX5AP gene expression in IS requires further studies.

The present study includes several limitations. Firstly, the expression levels of the FLAP protein were not explored in patients with IS and control subjects. Secondly, no significant differences were noted in the overall methylation levels of the promoter region of the ALOX5AP gene between IS cases and control subjects. Thirdly, a potential selection bias may have 
been present since the cases and controls were recruited from the same hospitals.

\section{Acknowledgements}

Not applicable.

\section{Funding}

The research reported in this publication was supported by a grant from the National Science Foundation of China-Henan United fund (grant no.U2004114).

\section{Availability of data and materials}

The datasets used and/or analyzed during the current study are available from the corresponding author on reasonable request.

\section{Authors' contributions}

XB, LX, XW and ZZ performed the experiments. HLZ, DY and BZ conducted the statistical analysis. XZ, YW, SY and YL were involved in study implementation and participant recruitment. YH, ZZ and XW wrote the manuscript. YH, HZ, YX and HD conceived the study and participated in its design and coordination. XB and LX confirm the authenticity of all the raw data. All authors read and approved the final manuscript.

\section{Ethics approval and consent to participate}

The study protocols were approved by the Ethics Committee on Human Research of Zhengzhou University and informed written consent was obtained from each participant. All experiments were performed in accordance with relevant guidelines and regulations.

\section{Patient consent for publication}

Not applicable.

\section{Competing interests}

The authors declare that they have no competing interests.

\section{References}

1. Hankey GJ: Stroke. Lancet 389: 641-654, 2017.

2. Tuttolomondo A, Pecoraro R, Casuccio A, Di Raimondo D, Buttà C, Clemente G, Corte VD, Guggino G, Arnao V, Maida C, et al: Peripheral frequency of $\mathrm{CD}^{+} \mathrm{CD} 28^{-}$cells in acute ischemic stroke: Relationship with stroke subtype and severity markers. Medicine (Baltimore) 94: e813, 2015.

3. Tuttolomondo A, Pinto A, Corrao S, Di Raimondo D, Fernandez P, Di Sciacca R, Arnao V and Licata G: Immuno-inflammatory and thrombotic/fibrinolytic variables associated with acute ischemic stroke diagnosis. Atherosclerosis 203: 503-508, 2009.

4. Tuttolomondo A, Di Raimondo D, Pecoraro R, Casuccio A, Di Bona D, Aiello A, Accardi G, Arnao V, Clemente G, Corte VD, et al; KIRIIND (KIR Infectious and Inflammatory Diseases) Collaborative Group: HLA and killer cell immunoglobulin-like receptor (KIRs) genotyping in patients with acute ischemic stroke. J Neuroinflammation 16: 88, 2019.

5. Rådmark O, Werz O, Steinhilber D and Samuelsson B: 5-Lipoxygenase, a key enzyme for leukotriene biosynthesis in health and disease. Biochim Biophys Acta 1851: 331-339, 2015.
6. Jala VR and Haribabu B: Leukotrienes and atherosclerosis: New roles for old mediators. Trends Immunol 25: 315-322, 2004

7. Colazzo F, Gelosa P, Tremoli E, Sironi L and Castiglioni L: Role of the cysteinyl leukotrienes in the pathogenesis and progression of cardiovascular diseases. Mediators Inflamm 2017: 2432958, 2017.

8. Fan Y, Chen H, Li A, Shi Y, Zhang Y, Feng Q, Sun Y, Zheng H and He Y: A promoter polymorphism (rs17222919, -1316T/G) of $A L O X 5 A P$ gene is associated with decreased risk of ischemic stroke in two independent Chinese populations. PLoS One 10: e0122393, 2015.

9. Ström JO, Strid T and Hammarström S: Disruption of the alox5ap gene ameliorates focal ischemic stroke: Possible consequence of impaired leukotriene biosynthesis. BMC Neurosci 13: 146, 2012.

10. Xu X, Sheng W and Liu L: Association between mRNA level of Pde4d and Alox5ap and hypertensive stroke as well as hypertension in rats. Zhonghua Yi Xue Yi Chuan Xue Za Zhi 24: 491-494, 2007 (In Chinese)

11. Domingues-Montanari S, Fernández-Cadenas I, del Rio-Espinola A, Corbeto N, Krug T, Manso H, Gouveia L, Sobral J, Mendioroz M, Fernández-Morales J, et al: Association of a genetic variant in the $A L O X 5 A P$ with higher risk of ischemic stroke: A case-control, meta-analysis and functional study. Cerebrovasc Dis 29: 528-537, 2010.

12. Matouk CC and Marsden PA: Epigenetic regulation of vascular endothelial gene expression. Circ Res 102: 873-887, 2008.

13. Chauhan G and Debette S: Genetic Risk Factors for Ischemic and Hemorrhagic Stroke. Curr Cardiol Rep 18: 124, 2016.

14. Yong D, Chao X, Hui WJ, Yu SY, Ye ZJ and Gang C: Recent progress in epigenetics. Sci Sin 1: 3-15, 2017.

15. Hammond SM: An overview of microRNAs. Adv Drug Deliv Rev 87: 3-14, 2015

16. Lindsay P, Furie KL, Davis SM, Donnan GA and Norrving B, et al: World Stroke Organization global stroke services guidelines and action plan. Int J Stroke Suppl A100: 4-13,2014.

17. Livak KJ and Schmittgen TD: Analysis of relative gene expression data using real-time quantitative PCR and the 2(-Delta Delta C(T)) Method. Methods 25: 402-408, 2001.

18. Moore DF, Li H, Jeffries N, Wright V, Cooper RA Jr, Elkahloun A, Gelderman MP, Zudaire E, Blevins G, Yu H, et al: Using peripheral blood mononuclear cells to determine a gene expression profile of acute ischemic stroke: A pilot investigation. Circulation 111: 212-221, 2005.

19. Sharp FR, Xu H, Lit L, Walker W, Pinter J, Apperson M and Verro P: Genomic profiles of stroke in blood. Stroke 38 (Suppl): S691-S693, 2007.

20. Baird AE: Blood genomics in human stroke. Stroke 38 (Suppl): S694-S698, 2007.

21. Asano S, Chantler PD and Barr TL: Gene expression profiling in stroke: Relevance of blood-brain interaction. Curr Opin Pharmacol 26: 80-86, 2016.

22. Li Y, Li Z, Zhang X, Yan C, Kang J, Liang Z, Liu S, Feng X and Han Y: Association of ALOX5AP haplotypes with susceptibility to coronary artery disease in a Chinese Han population. Eur J Intern Med 23: e119-e123, 2012.

23. Bruno F, Spaziano G, Liparulo A, Roviezzo F, Nabavi SM, Sureda A, Filosa R and D'Agostino B: Recent advances in the search for novel 5-lipoxygenase inhibitors for the treatment of asthma. Eur J Med Chem 153: 65-72, 2018.

24. Chen Z, Zheng J, Liu W, Yang K, Li K, Huang B, Zhu R, Lu X and Li L: The SG13S114 polymorphism of the ALOX5AP gene is associated with ischemic stroke in Europeans: A meta-analysis of 8062 subjects. Neurol Sci 38: 579-587, 2017.

25. Shi Y, Xu L, Feng Q, Li A, Jia J, Xu Y, Yang D, Zhang Y, Zhang X, Zhao H, et al: Allele-specific methylation contributed by CpG-SNP is associated with regulation of ALOX5AP gene expression in ischemic stroke. Neurol Sci 39: 1717-1724, 2018.

26. Cao XL, Yin RX, Huang F, Wu JZ and Chen WX: Chromosome 9 p21 and ABCA1 genetic variants and their interactions on coronary heart disease and ischemic stroke in a Chinese Han population. Int J Mol Sci 17: 586, 2016.

27. Lin HF, Hsi E, Liao YC, Chhor B, Hung J, Juo SH and Lin RT: Demethylation of circulating estrogen receptor alpha gene in cerebral ischemic stroke. PLoS One 10: e0139608, 2015.

This work is licensed under a Creative Commons Attribution-NonCommercial-NoDerivatives 4.0 International (CC BY-NC-ND 4.0) License. 